\title{
Central venous catheter used for recording intracardiac electrocardiogram $A$ safe and reliable method for registering atrial potentials using a new device connected to the central venous catheter
}

\author{
F. Urthaler ${ }^{1}$ and J. Halter \\ From the Department of Internal Medicine, Kantonsspital \\ - University of Zurich, Switzerland
}

- A simple bedside method for recording the right atrial electrocardiogram using the conventional central venous catheter is presented. Satisfactory registering is obtained with the help of a

" silvered metallic T-shaped device positioned between intracath and infusion-set, with saline solution as conductor.

The identification and differentiation of atrial potentials are important for adequate analysis of different arrhythmias. Though the conventional electrocardiographic tracings are usually sufficient, additional methods are often necessary (Hellerstein, Pritchard, and Lewis, 1949; Sterz, 1960; Vogel et al., 1964). The purpose of this paper is to describe a new technique of recording intracardiac electrocardiograms using an 'Intracath'2 positioned in the right atrium.

Central venous catheters are routinely inserted through a medial antecubital, an external jugular, or a subclavian vein at the bedside in an intensive care unit. After intraatrial placement of the catheter tip, its position is controlled radiologically. The external end is connected to a special metallic - piece as illustrated in Fig. $I$.

This $T$-shaped device is interposed be"tween an intracath and a three-way stop-cock which allows infusion of either saline or other solutions (Fig. 2). It also permits a stable contact between the terminal of an electrocardiographic lead and saline flowing through the * cross-arm of the T piece. For the electrocardiographic recording the praecordial lead is plugged into the $\mathrm{T}$-shaped metallic device. Received 3 April r970.

1 Present address: University of Alabama Medical Center, CVRCT-207 BMS Building-Birmingham, Alabama 35233, U.S.A.

2 Deseret intracath (B) intravenous catheter placement unit, Barol-Davol Ltd., Clacton-on-Sea, Essex, England.
Good electrical conduction has been obtained by two principles: the conductor in the catheter is a non-moving isotonic or hypertonic saline solution, and the metallic device has been silvered. Except for the brief periods necessary for electrical recording, this set permits permanent infusion. This system is easily and

FIG. I (I) T-shaped metallic device;

(2) three-way stop-cock; (3) intracath;

(4) infusion solution; (5) saline solution; and

(6) electrocardiogram recording.

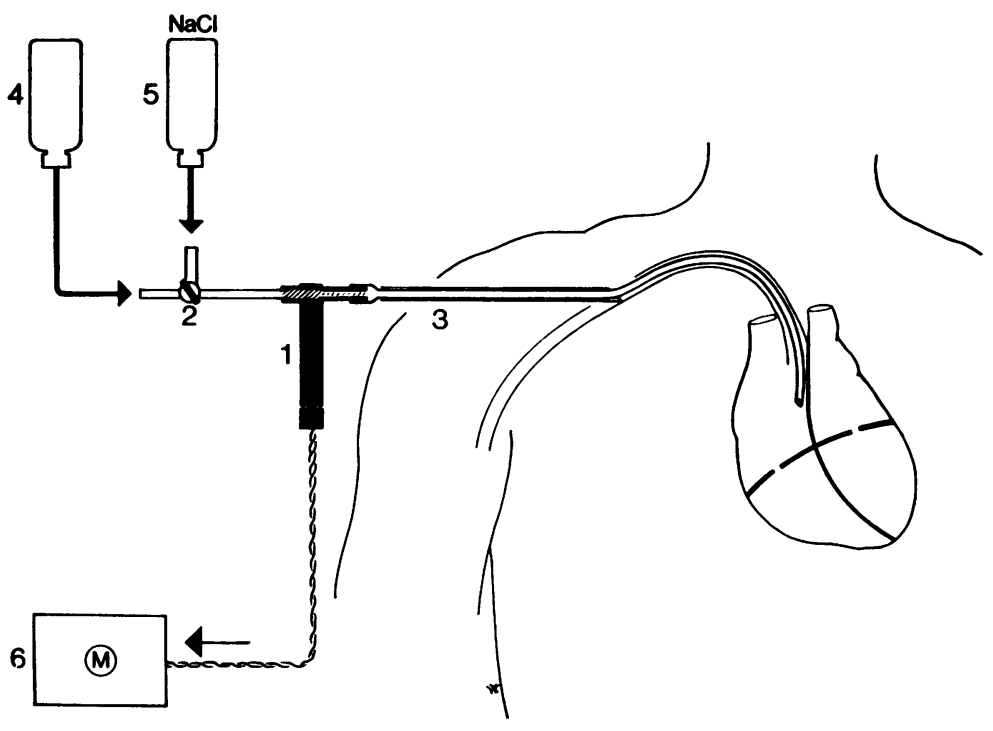


rapidly installed and can be routinely used in intensive care units.

The example shown in Fig. 3 serves to illustrate the quality of the atrial recording in a patient with a tachycardia and how it is possible to differentiate between supraventricular and ventricular origin of the arrhythmia. The upper tracing shows one of the conventional leads (III), the lower the right atrial recording. Lead III as well as the other conventional leads did not reveal the atrial potentials which are clearly visible on the intracardiac electrocardiogram registered by this method. The total AV dissociation proves that the presented case has a ventricular tachycardia.

We are grateful to Professor P. G. Frick for advice in the preparation of this paper and to Messrs. J. Neff and B. Trümpler for technical assistance. We also thank Mr. H. P. Weber for preparing the diagrams.

\section{References}

Hellerstein, H. K., Pritchard, W. H., and Lewis, R. L. (1949). Recording of intracavitary potential through a single lumen saline filled catheter. Proceedings of the Society for Experimental Biology and Medicine, 71, 58.

Sterz, H. (1960). Intrakardiale Elektrocardiographie. Archiv für Kreislaufforschung, 33, 259.

Vogel, J. H. K., Tabari, K., Averill, K. H., and Blount, S. G. (1964). A simple technique for identifying $\mathrm{P}$ waves in complex arrhythmias. American Heart fournal, 67, 158.

FIG. 3 Comparison of conventional recording of lead III (upper tracing) and intra-atrial recording (lower tracing).

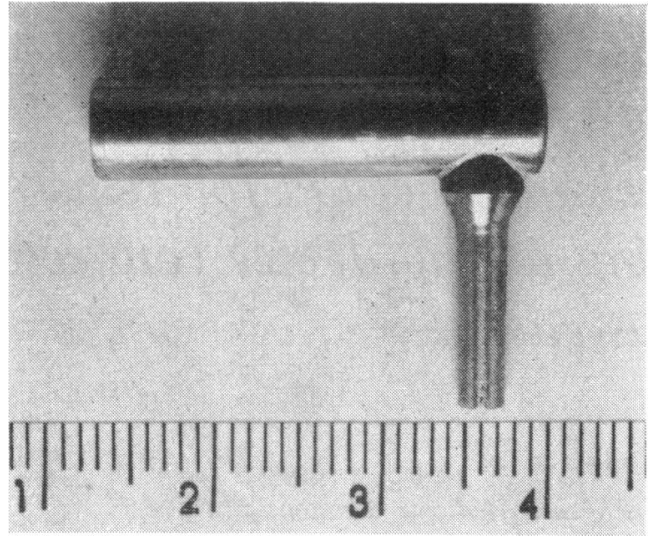

FIG. 2 T-shaped metallic device.

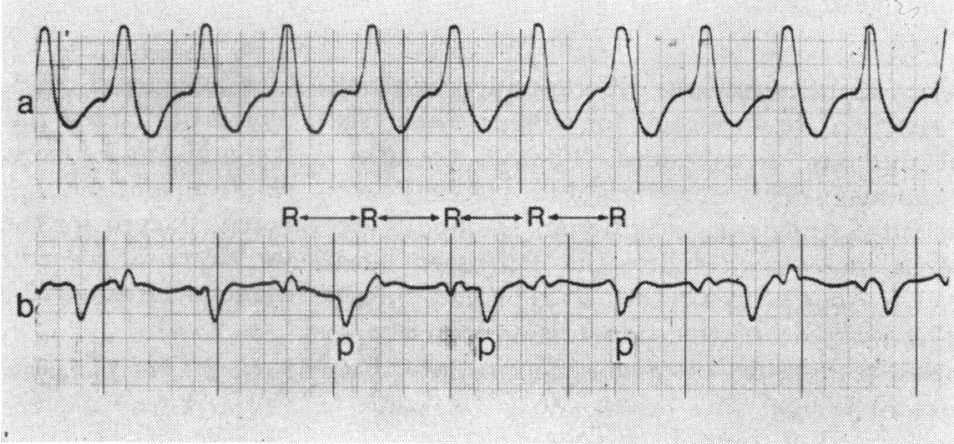

